\title{
LA CIUDAD NEGADA
}

Santiago Diomedi Ollier ${ }^{1}$

\section{Introducción}

El presente trabajo se ocupa del proceso de producción de una ciudad intermedia (Gravano, 2005; Boggi, 2008) de la Provincia de Buenos Aires, puntualmente en Olavarría. Fundada en 1867 se encuentra en el centro de la mencionada provincia y es la ciudad cabecera del partido homónimo, de perfil agrícola e industrial (cuya actividad predominante es la industria de extracción pétrea); cuenta con una población de 86.721 habitantes según el último censo realizado en 2010 por el Instituto Nacional de Estadística y Censos (INDEC). El partido de Olavarría, fundado en 1878 engloba, además de la ciudad cabecera, las localidades y parajes de Sierras Bayas, Loma Negra, Sierra Chica, Hinojo, Colonia Hinojo, Recalde, Blanca Grande, Colonia San Miguel, Espigas, Colonia Nievas, Santa Luisa y, Villa La Serranía totalizando 111.708 habitantes (INDEC, 2010). La figura 1 detalla la localización del partido en el mapa de la Provincia de Buenos Aires y la disposición de las localidades dentro del mismo.

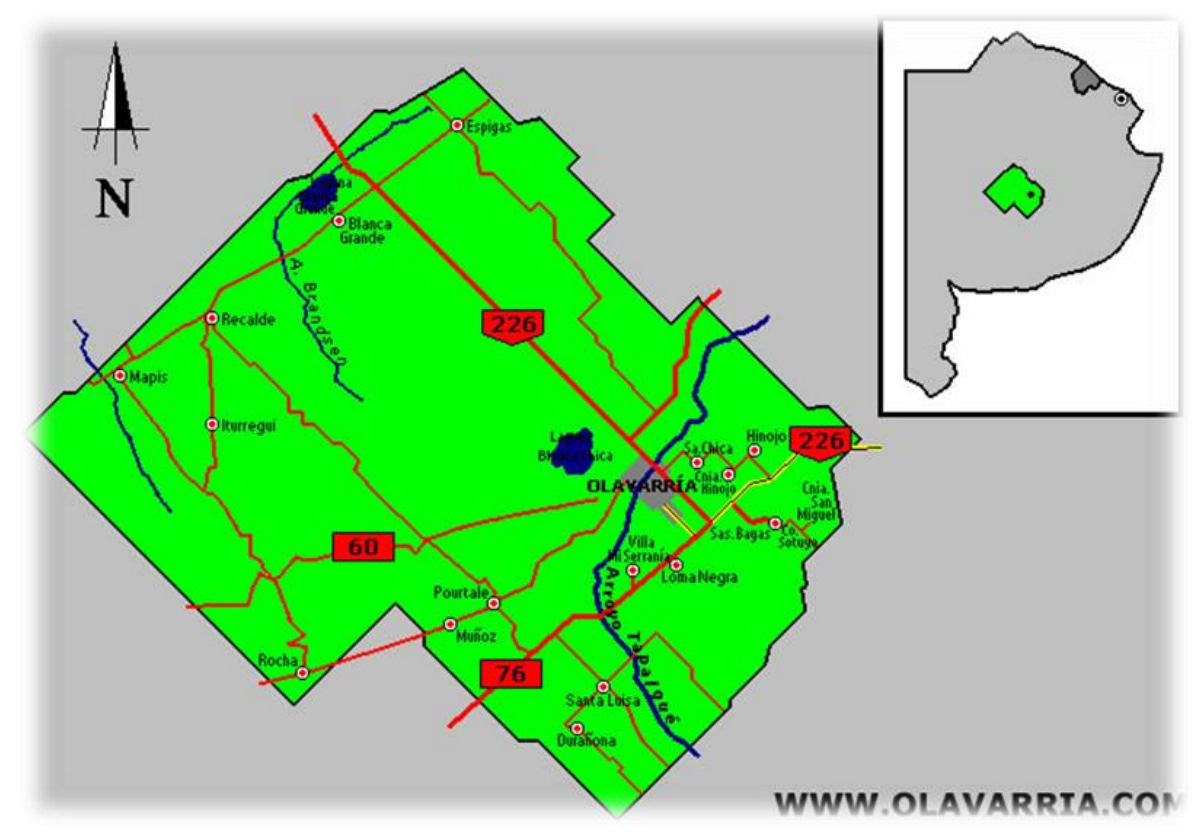

Figura 1

\footnotetext{
${ }^{1}$ Universidad del Centro de la Provincia de Buenos Aires, Argentina.
} 
El trabajo se focaliza en los modos en que acontece la lucha por el derecho de hacer la ciudad, "entendiendo por ello a generar las condiciones necesarias para que ésta cumpla su 'rol"' (Sosa, 2014: 31) entre los agentes (Giddens, 1995) que a diario la producen y la consumen. Se busca dar cuenta de la articulación histórica y relacional del acceso a los consumos colectivos en el marco de las luchas y las disputas entre los diferentes (y diversos) actores sociales. Esta lucha por hacer la ciudad no se da únicamente entre actores. Involucra principalmente a los imaginarios urbanos entendidos estos como "el conjunto de representaciones simbólicas, imágenes icónicas, identidades emblemáticas, racionalidades, creencias y valores que se referencian (...) en el espacio urbano" (Gravano, 2014: 3-4).

Se hace hincapié en la segregación simbólico-espacial y en la construcción de imaginarios estigmatizantes como detonantes de/en la producción de sentidos generadores de una acción colectiva encaminada a disputar el derecho a hacer la ciudad, tanto en el plano material como simbólico. Por segregación simbólico-espacial entendemos al uso diferencial y diferenciado que los ciudadanos hacen de los consumos urbanos, entendidos estos como la infraestructura de servicios, seguridad, educación, entretenimientos, consumos culturales, etc. que contiene el sistema urbano en su conjunto. Esta segregación daría lugar a diversas acciones colectivas que apuntan a revindicar el derecho a esos consumos, teniendo en cuenta que los mismos abarcan la totalidad del sistema urbano, el objeto de lucha sería la ciudad misma.

¿Cómo se dan estas luchas? ¿Cuáles son las fortalezas y las limitaciones de estos movimientos? Si el lugar que sus protagonistas ocupan en la sociedad es relevante ¿de qué manera afecta esto las posibilidades de acceder a los consumos colectivos? Por otra parte, y a fines de realizar un análisis que mantenga una perspectiva dialéctica, nos preguntamos por la relación que une el acceso (o la posibilidad de acceso) a los consumos colectivos y el lugar ocupado por los agentes en la sociedad. Estos fueron los interrogantes que dispararon las primeras aproximaciones a la problemática.

El diseño metodológico se orienta hacia la investigación cualitativa en tanto se propone abordar el objeto de estudio desde el uso de técnicas afines a dicho enfoque: observaciones, entrevistas, construcción de historias de vida, etc. Complementando con información documental a fines de reconstruir, a partir de la memoria colectiva, la historia de los barrios e instituciones seleccionadas. Coincidimos con Mezzano en que "la historia está conformada por historias de vida singulares, que transcurren en el seno 
de las instituciones." (Mezzano en Taborda y Leoz, 2013: 255). Dicha metodología no le es ajena a la Antropología en tanto la misma representa un aporte de relevancia en la construcción del punto de vista emic.

El proceso de investigación hasta aquí ha permitido seleccionar como referentes empíricos a dos barrios de la ciudad de Olavarría: Mariano Moreno y SCAC o Villa Magdalena, este último se ubica en una zona periférica de la ciudad. En el ámbito de cada barrio se han elegido las Organizaciones de la Sociedad Civil (OSC) como actor relevante de la organización barrial, en tanto es desde dichas organizaciones que se organiza la acción colectiva (Brook, 1997; Sabarots y Sarlingo, 1995). A continuación (figura 2) señalamos la localización de cada uno en el mapa de la ciudad, el rojo corresponde a Mariano Moreno y el azul a SCAC.

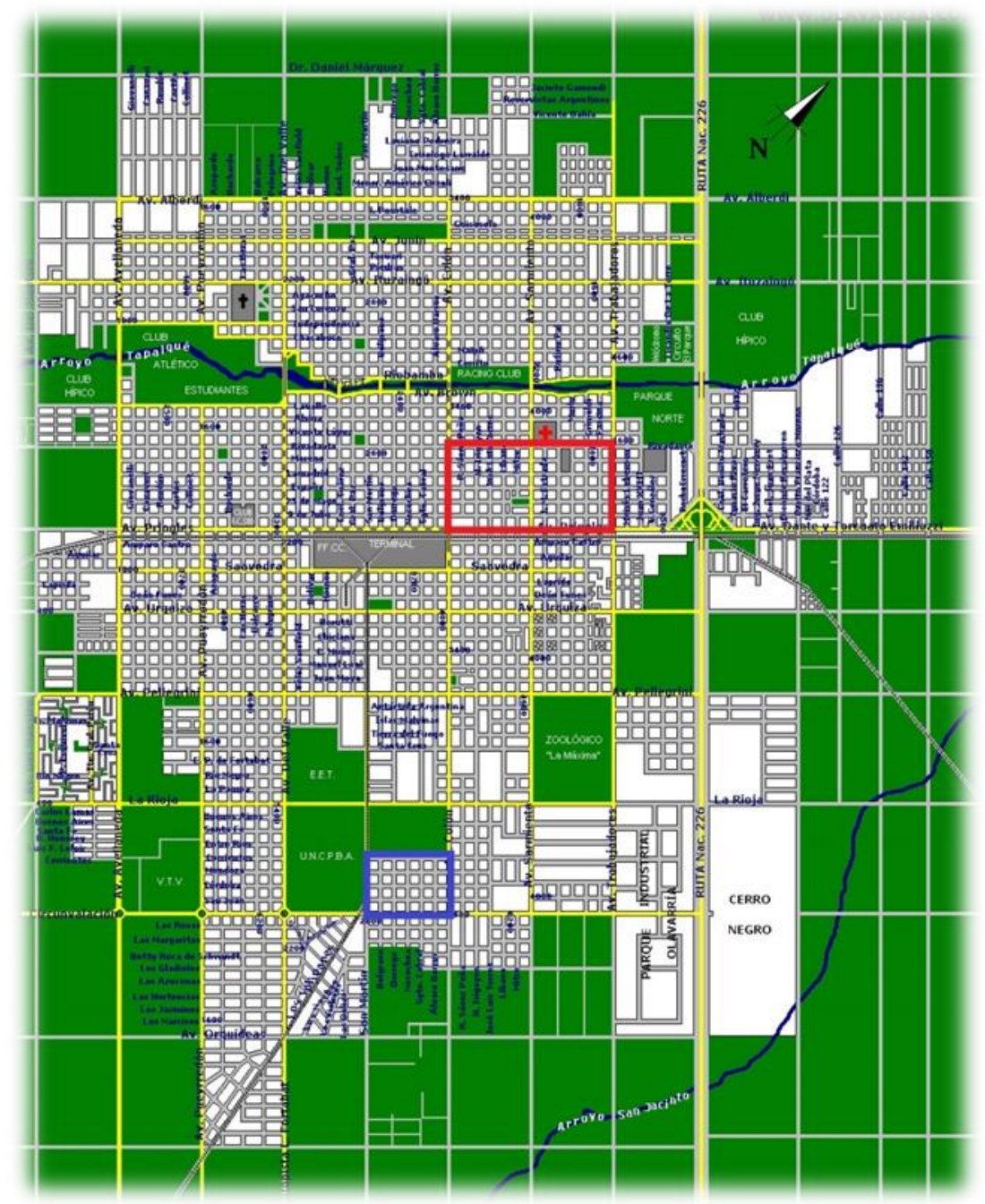

Figura 2 


\section{La ciudad luchada}

El abordaje de problemáticas urbanas y su vinculación con la construcción de imaginarios estigmatizantes se ha ido constituyendo como un área de particular interés y durante 2014 se comenzó a indagar en torno a las problemáticas urbanas. En dicha ocasión se enfocó en la construcción de imaginarios estigmatizantes en relación al concepto de barrio mancha:

\footnotetext{
Los barrios pobres- e incluso algunos de los medios- terminan apareciendo en el imaginario como manchas. En efecto, a pesar de faltar el referente empírico (las villas miseria) las imágenes de manchas negras urbanas aparecen en el imaginario urbano de Olavarría mediante la estigmatización de ciertos barrios de vivienda social (...) (Gravano, 2005: 90).
}

El núcleo de la problematización orbitó en torno a dos grandes ejes: 1) la tensión que se registra entre la construcción de imaginarios por parte de los vecinos de un barrio y entre quienes habitan otras zonas de la ciudad, y 2) las políticas de gestión territorial llevadas adelante desde el gobierno municipal, que se materializaron en la división de la ciudad en sectores, en el denominado Servicio Municipal Territorial (SMT).

En relación a estos ejes, se indagó acerca de una división territorial que, al tiempo que materializaba la descentralización del Estado municipal, parecía dar cuenta de una clara intencionalidad en tanto el agrupamiento territorial, a partir de un solo movimiento, generó un doble efecto: unificó a los barrios mancha a la par que los escindió de los barrios "distinguidos".

Ambos ejes partían de la propuesta de Jordi Borja (2003) que plantea que muchos nacen ciudadanos, pero otros se hacen, se hacen a través de sus luchas, de la reivindicación constante por los derechos de la ciudad, de obtener los que no tienen y de asegurar los que sí: "el ciudadano lo es en tanto que ejerce de ciudadano" (Ibíd.: 25). Por otra parte, los derechos de la ciudad son los que se derivan de vivir en ella, produciéndola y consumiéndola: derecho a la vivienda, a una vida digna, a usar los servicios que la ciudad brinda (o debe brindar) para quienes la habitan. Hay sectores que quedan al margen, a quienes no se les garantiza el cumplimiento de los derechos. Son estos sectores los que luchan por su reivindicación llevando adelante, en ciertas ocasiones, acciones, si bien legítimas, ilegales, como la usurpación de terrenos, o como señala Gravano (2013), legitimando acciones ilegales. 
En coincidencia con la misma problemática, durante 2015 se continuó con el trabajo de campo en el marco de una serie de reclamos por asfalto realizado por parte de los residentes de SCAC (sigla de "Sociedad Cementos Armados Centrifugados", fábrica de la cual el barrio tomó su nombre). En dicha ocasión, el eje se desplazó hacia la lucha por el acceso a los consumos colectivos, y como mencionamos, partiendo de la visión de Jordi Borja (2003) de que el ciudadano no nace, sino que se hace, se analizó el conflicto en clave de la lucha por los beneficios que la ciudad debería otorgar a quienes la producen y de la acción colectiva que se organiza al no cumplirse con determinados derechos, haciendo uso, además, del concepto de Movimientos Sociales Urbanos (Castells, 1974; Gravano, 2013). Se problematizó la relación entre el Estado Municipal y el grupo de vecinos que sostuvieron durante varias semanas un corte de calle, relación que, lejos de ser cristalina, se mostró por demás compleja e inextricable (Fernández y Diomedi Ollier, 2015). En análisis de estos ejes resultaron en aporte clave para nuestra investigación, en tanto logramos visibilizar el rol que la acción colectiva cumple en torno al reclamo por los consumos urbanos pero sin obviar la relación con el que consideramos el actor más estructural: el Estado (municipal en este caso). Otro aporte de relevancia para nuestro análisis fue el rol de los medios de comunicación en esta construcción, que si bien no consideramos como de influencia absoluta, no podemos negarle determinada relevancia, en tanto dos eventos ocurridos en la misma noche y en dos barrios de la ciudad con distinta "reputación" (SCAC y Pueblo Nuevo) fueron tratados de manera diferencial. Más puntualmente lo ocurrido en SCAC fue notablemente cubierto por los medios y lo de Pueblo Nuevo ni siquiera mencionado.

En relación con lo anterior, Yuri Romero señala que:

El «derecho a la ciudad» ha sido trabajado por varios autores con el interés de abordar una problemática social en los estudios sobre ciudad. Lefebvre (1978:138) lo definió como el derecho a una vida urbana transformada y renovada donde se recobren e intensifiquen las capacidades de integración y participación de sus habitantes. Otros autores, como Ansay y Schoonbrodt (1989:38), lo definieron como el derecho a la reivindicación legítima de cada individuo de ser partícipe de una forma de vida colectiva cada vez más socializada, reclamando del pacto social los recursos institucionales necesarios para su desenvolvimiento en la ciudad (Romero, 2006:2).

Esto puede enlazarse con el planteo de Borja de que se es ciudadano en tanto se ejerza como tal, es decir, la ciudad como escenario y objeto de lucha. El derecho a cuidad no sería únicamente el acceso a los consumos colectivos, sino también el 
derecho a reclamar por ese acceso, en tanto la ciudad es una producción histórica y socialmente construida.

Esta reproducción es, creemos, producto de una constante lucha por el acceso a hacer la ciudad y nos proponemos analizarla desde una perspectiva holística, recuperando la dimensión política de este proceso que, sostenemos, es transversal a los procesos de lucha, entendiendo por estos a las acciones colectivamente emprendidas en pos de reivindicar, obtener y/o mantener una serie de derechos, disputa en la cual entra en juego la propia ciudad (Harvey, 2014).

En definitiva, la lucha por el acceso a "hacer" la ciudad, como todo conflicto creemos, desconocería (o conocería demasiado bien) que el acceso desigual es estructural a la ciudad, al sistema capitalista y al Estado capitalista. En palabras de Gramsci, esta relación de fuerzas sociales se encuentra

Estrechamente ligada a la estructura, objetiva, independiente de la voluntad de los hombres (...). Sobre la base del grado de desarrollo de las fuerzas materiales de producción se dan los grupos sociales, cada uno de los cuales representa una función y tiene una posición determinada en la misma producción. (1980: 12).

A esto podemos añadir que el desarrollo de las fuerzas productivas en el sistema capitalista, mediante la extracción de plusvalor, y en tanto el único generador de riqueza es el trabajo, plantea como estructural la desigualdad. En el análisis marxista clásico esta desigualdad se corporizaba entre quienes poseen medios de producción y quienes solo pueden vender su fuerza de trabajo. Partimos de considerar que vivimos bajo la égida de un Estado capitalista, y que más allá de las formas ideológicas que adopten los gobiernos, el país se inscribe en los circuitos comerciales capitalistas, es por esto que las desigualdades que se dan en el plano productivo se reflejarían en las condiciones materiales de existencia en tanto la ciudad es, en lo formal, para todos, pero en la práctica muestra sus grietas.

El Estado, como garante del acceso a los consumos colectivos, juega un papel fundamental en tanto atraviesa de forma transversal las acciones de los grupos. Su accionar (el del Estado) como actor estructural, si bien no determinante de manera definitiva, colabora a mantener la desigualdad estructural en el acceso a los consumos colectivos. Es determinante cuando, por ejemplo, decide licitar alumbrado o asfalto en tal o cual barrio, los vecinos o las OSC no podrían por sus propios medios contratar a una empresa para llevar a cabo tales mejoras, por otro lado no es tan determinante 
cuando esas mismas organizaciones emprenden el reclamo para acceder a tales beneficios. En este sentido la definición de Castells de Movimientos Sociales Urbanos (MSU) señala que estos surgen de una acción colectiva orientada a la reivindicación por las necesidades y los consumos urbanos; estas son para Castells las problemáticas urbanas que define como "una serie de actos y de situaciones de la vida cotidiana cuyo desarrollo y características dependen estrechamente de la organización social general" (1974: 3). Estos MSU suelen ser corte coyuntural y organizan su acción en torno a reclamos puntuales.

Aun así hemos de ser precavidos, esto no quiere decir que los movimientos que surgen de estas coyunturas apunten a "rehacer" la estructura, en este sentido, a los discursos por el acceso a los beneficios que la ciudad otorga subyace un deseo de "ser como", con matices claro está, pero parecería que en algún punto desean la ciudad "para sí mismos" (o que esa ciudad con asfalto y alumbrado llegue a ellos) y una vez arribada (o cumplidas ciertas expectativas) el conflicto mermaría. El caso de las protestas en Barrio Dorrego por el pavimento es un ejemplo, una vez obtenido el mismo el conflicto disminuyó. Estos movimientos parecerían no reflexionar sobre la naturaleza del sistema que lo coloca donde están.

Cabe distinguir, además, entre acceso desigual y no-acceso a los consumos colectivos, o dicho de otro modo, no sólo haremos hincapié en las zonas periféricas sino que intentaremos establecer relaciones entre los barrios seleccionados, en tanto creemos que es a través del análisis de dichas relaciones que podemos ver los modos en que los sujetos y las organizaciones forman parte de esta lucha. Concretamente hemos seleccionado una organización de cada barrio así como también vecinos de los mismos que no participan activamente de la organización barrial en términos formales, pero que habitan el barrio hace mucho tiempo, lo cual privilegia de algún modo el registro de su discurso sobre la realidad del mismo. Las organizaciones son la Sociedad de Fomento Mariano Moreno (SFMM) y la Sociedad de Fomento Villa Magdalena (SFVM). 


\section{Metáforas para el análisis de lo urbano}

Para el análisis de estas cuestiones proponemos dos metáforas contrapuestas: plasticidad y elasticidad urbanas. La plasticidad, según la mecánica de sólidos, es un comportamiento característico de ciertos materiales que, al superar su límite elástico, sufren deformaciones permanentes e irreversibles, el ejemplo clásico de esto son las bandas elásticas, las cuales al exponerse a cierta tensión no recuperan su forma o se desgarran. A partir de esto nos proponemos construir una metáfora aplicable a la lucha por el derecho de hacer la ciudad. Cabe aclarar algunos puntos antes de comenzar, (1) en primer lugar no sostenemos que la construcción del espacio urbano posea un "límite elástico", (2) tampoco veremos los cambios como deformaciones, en todo caso hablaremos de nuevas formaciones, (3) por otra parte no entendemos que la ciudad posea una forma original, lo que nos interesa retener son las características de permanente e irreversible ya que así parecería mostrarse la ciudad para quienes, desde un perspectiva emic, "quedan fuera" de la misma.

Recuperando el trabajo de campo realizado divisamos que el discurso de los agentes se encuentra atravesado por una percepción que parece ser común: "no le importamos a nadie". Citamos a continuación un fragmento de una entrevista a una vecina de SCAC con quien establecimos contacto durante la protesta de 2015 que muestra claramente tal sentir:

\footnotetext{
“A mí se me murió una hijita, en el 95, de meningitis, y está enterrada en el Cementerio y me gusta ir a llevarle unas flores, porque una nunca deja de ser madre (se emociona) ¿viste que aparecieron esa cruces en la virgen de la loma?2 Bueno, yo había ido al cementerio y dónde está mi nena estaba la tierra removida, y es en el mismo sector de donde eran los huesos que aparecieron, yo pregunté qué había pasado y no me dijeron nada, me dijeron que estaba ahí el cajoncito, pero que estaba más abajo porque habían arreglado, pero para mí que la sacaron y la tiraron donde aparecieron las cruces, todos me dicen "esa no es tu hija" (le tiembla más la voz) yo sé que no es, pero es bueno tener un lugar para ir y dejar una flor aunque sea, yo me siento más cerca (baja la vista y el recuerdo parece volverse más doloroso por la situación actual). Y ahora no me dejan ver si el cajoncito está iyo quiero ver que esté! y si no me dejan es porque la tiraron, un día me voy a ir yo con una pala porque yo pagué todo cuando pasó lo de la nena y pagué el lugar para poder tener donde ir, y si no hubiera pagado tampoco tienen derecho a hacer eso".
}

\footnotetext{
${ }^{2} \mathrm{~A}$ mediados de 2015 se hallaron, en el sector de un basural, lápidas, huesos y restos de tumbas del cementerio municipal.
} 
Como mencionamos antes, la ciudad, incluso la de los muertos, parece terminada y fueron excluidos. En este sentido la metáfora de la plasticidad se muestra pertinente: la acción colectiva estaría dirigida precisamente a combatir por ser incluido en una ciudad que nunca llega.

En tanto se propone una visión dialéctica de los procesos de lucha, se muestra pertinente la construcción de una contra-metáfora, o mejor dicho una metáfora complementaria, la de la elasticidad, que es la propiedad de ciertos materiales de recuperar su forma original cuando cede la tensión. Las aclaraciones a esto son la mismas que a la plasticidad, lo que recuperamos es la propiedad de adoptar determinada forma, es decir la maleabilidad.

Desde el plano analítico sostenemos que este proceso muestra una contracara, en tanto SCAC, por ejemplo, no se encuentra fuera de la ciudad, sino que es parte integral en su construcción simbólico-espacial en tanto "sea lo que tiene que ser": depositario de males, chivo expiatorio donde se vuelcan los problemas de la ciudad. En definitiva, tanto SCAC como Mariano Moreno hacen la ciudad, los primeros desde donde no desean y los segundos desde donde los primeros aspiran a hacerlo.

Con el propósito de evitar confusiones en torno al "hacer", proponemos una distinción inicial a fines de ordenar la lectura. En primer término todos hacen la ciudad, por lo tanto al hablar de hacer nos referimos a la producción de la ciudad en un sentido amplio.

Dentro del mismo, y a modo de hipótesis, diferenciamos dos modos de hacer la ciudad, por un lado un hacer plástico, que sería aquel ejercido por quienes sufren la consecuencias de un modelo de desigualdad estructural en el acceso a los consumos colectivos como producto/productor de segregaciones y estigmatizaciones, y por el otro un hacer elástico que sería producto de la combinación entre las condiciones mencionadas y el ejercicio de la hegemonía por parte de determinados sectores. Cabe aclarar que dicha distinción, puramente analítica, no es de ninguna manera estática, en tanto la lucha por hacer la ciudad es un proceso dinámico. Intentaremos explicitar estas cuestiones, por "hacer plástico" (y su relación con la desigualdad estructural en el acceso a los consumos colectivos) entendemos que determinados barrios (SCAC en nuestro caso) ocupan una posición de desfavorable respecto de determinados otros (Mariano Moreno) pero esto no significa que no participen en la producción de la ciudad. 
Por otra parte hablamos de un "hacer elástico". Barrios como Mariano Moreno gozan de una amplia estructura de servicios y con una posición en el imaginario urbano que lo coloca como un barrio con un alto nivel de vida y con una Sociedad de Fomento por demás pujante. Esta situación contrasta con la realidad de SCAC y es por tal motivo las posibilidades de Mariano Moreno de ver satisfechos sus reclamos son sensiblemente mayores que las de SCAC, Y es por eso que sostenemos que goza de cierta elasticidad.

Ahora bien ¿cómo mirar la lucha por hacer la ciudad desde estas metáforas? En primer lugar, y casi como una obviedad, desde las dimensiones hegemónicas del imaginario local (Gravano, 2005) sobre Mariano Moreno y SCAC. Mariano Moreno, visto aquí a través de la Sociedad de Fomento que lleva el nombre del barrio, que a través de convenios con la Municipalidad, contactos con la Iglesia y demás, se muestra como un actor que goza de una posición relevante en la ciudad. Un miembro de la institución, ante la pregunta sobre la relación con el municipio expresó “(... ¿ ¿ sabés que pasa? que sentarse a hablar con nosotros es sentarse a hablar de plata porque no tenemos grandes necesidades y podemos esperar que vengan", en la misma entrevista habló de las actividades que se realizan en la sede, del balance positivo que la organización muestra anualmente en términos económicos y de la infraestructura con que cuentan.

El lugar que Mariano Moreno ocupa en la historia de la ciudad surge continuamente en los discursos de quienes se han visto ligados a la Sociedad de Fomento. Un ex-presidente recordó durante una entrevista, los bailes, las abultadas recaudaciones, las relaciones con personajes relevantes de la ciudad. En definitiva, Mariano Moreno se erige tanto como "modelo" de organización barrial como de barrio. El mismo entrevistado, recordando sus primeros años en el barrio, señaló a la escuela 50 como "hija de la SFMM". Una Sociedad de Fomento "comprometida" con el bario, actividades, capacitaciones, etc. Discurso filantrópico que parecería estar en las mismas bases de su fundación, tal como recordó Gladys, hija de quién donara el terreno donde se levantó la primera sede de la SFMM:

Aca era todo campo, había indios por allá [refiere a la actual zona de barrio Mataderos3], bah todavía son indios, namás que ahora hablan ¡si vos vieras como vivían!, ayudamos a mucha gente, el terreno de la iglesia era de mi familia, igual que varias manzanas de la zona, y nunca se les cobró un centavo, cocinábamos, tejíamos, todo para ayudar, y nunca pedimos nada a cambio.

\footnotetext{
${ }^{3}$ Mataderos es un barrio periférico de Olavarría, se encuentra en el centro-este del casco urbano.
} 
Estos posicionamientos de la SFMM frente a la ciudad y a los diferentes gobiernos municipales, darían cuenta de la elasticidad (o del hacer elástico) con que Mariano Moreno cuenta.

Ahora bien, no sería correcto afirmar que el barrio ocupe solo esta dimensión del hacer la ciudad. Es posible ver la propia plasticidad de Mariano Moreno (o de la SFMM en particular) a través de la relación con el municipio. Si la única relación con el municipio es en términos económicos, e incluso poniendo en duda dicha afirmación, no estamos señalando una relación de intercambio superflua o irrelevante. Recuperando el concepto de capital entendido en términos de Bourdieu (1979) como los "recursos puestos en juego en los diferentes campos: capital económico, capital cultural y capital social (la red de relaciones movilizables)" (Giménez 2002: 7-8). Los distintos capitales poseen, a su vez, la característica de poder reconvertirse unos en otros, y el capital económico se muestra como uno que goza de gran maleabilidad, entonces "hablar de plata", que no suele ser poca cosa, lo es aún menos. Eso que el presidente señala como una fortaleza sería lo que condiciona el universo de acciones de la organización. Sin intenciones de ser contra fácticos, los bolsillos de la sociedad civil, pueden estar más o menos abultados, pero las arcas estatales pocas veces suelen mermar, y en diferentes etapas de su historia la SFMM necesitó del financiamiento estatal en forma de, por ejemplo, subsidios y convenios (algunos vigentes). Es por eso que señalamos esto como un indicador de la plasticidad en Mariano Moreno. Mención aparte merece el valor simbólico que una fluida relación con el Estado le insufla a la SFMM. Por otra parte la dimensión histórica del barrio da cuenta de que en sus orígenes (finales de siglo XIX y principios de siglo XX) ocupó una zona periférica de la ciudad. Esta característica en particular encuentra puntos de contacto con la investigación de Ariel Gravano respecto de los imaginarios de la ciudad de Olavarría donde postula que "diacrónicamente [el actual barrio] Pueblo Nuevo también parece haber sido barrio-mancha" (2005: 83).

Es necesario preguntarse si la periferia de la Olavarría de hace 100 años puede equipararse con la periferia de hace 30-40 años, que es cuando comienza a poblarse la zona que hoy es Barrio SCAC/Villa Magdalena. Inicialmente nos inclinamos a pensar que cada época construye su propia periferia, y si bien pueden mostrar similitudes, también contarán con sus propias especificidades. Como hipótesis de trabajo podemos decir que el proceso de expansión de la ciudad capitalista construye periferias a su paso, y que si bien el transcurrir histórico (y social) de cada barrio puede reconvertir esa 
imagen de barrio mancha, en la memoria colectivamente construida tal situación prevalecería y podría mostrar un hilo del cual "tirar" para analizar la plasticidad de Mariano Moreno.

Por otra parte se muestra pertinente recuperar de nuestro trabajo de campo dos entrevistas a vecinos de cada uno de los barrios, por un lado un ex-presidente de la SFMM y por el otro a Norma, autoproclamada como una de las vecinas más antiguas de SCAC. El ex-presidente, que cumplió funciones durante más de dos décadas, nos relató que fue invitado a la inauguración del Policlínico Ferroviario durante la década de 1970 (actual Escuela Superior de Ciencias de Salud de UNICEN) de la cual participó Albano Harguindeguy, ministro del Interior de la última dictadura militar, procesado por crímenes de lesa humanidad a la espera de juicio al momento de su fallecimiento. Norma, por su parte, se mudó a los terrenos que hoy ocupa Barrio SCAC durante la misma época. En ese momento una de las pocas edificaciones en la zona era la fábrica de premoldeados de cemento que dio posteriormente nombre al barrio. Podemos ver aquí dos historias de vida e intentar reconstruir un proceso a través de ellas: a la par que Norma se veía expulsada hacia los límites de la ciudad durante el gobierno militar un miembro de SFMM era invitado a una inauguración con representantes de la misma dictadura.

Podría pensarse que todo esto se reduce a la antinomia clases-dominantes/clasesdominadas, quizá en cierto punto lo sea, pero no en términos del tipo "Mariano Moreno vs. SCAC”, la realidad se muestra más compleja. Durante 2016 se licitó la red cloacal y el asfaltado de 11 cuadras en SCAC. Nuestras recorridas por el barrio parecen señalar que 11 cuadras no abarcarían la totalidad de barrio, contando las casas que dan a las diferentes calles la cuenta sería de entre 25 y 30. Una conversación con Norma (vecina de SCAC) resultó en una declaración que merece ser recuperada. Ante nuestra pregunta sobre el asfalto nos señaló “iSi! 11 cuadras ¿viste?”. Preguntamos - ¿11 cuadras nada más?- a lo que respondió con mucha seguridad "Es todo el barrio". Breve y categórico, la realidad física y espacial del barrio contrasta con lo que el barrio es para Norma. Con realidad nos referimos a las calles que delimitarían el barrio SCAC/Villa Magdalena, que engloban unas 36 cuadras con calles de tierra. En este escenario, las 11 licitadas parecerían ser insuficientes. Somos conscientes del ritmo con que se asfaltan las calles, pero al menos aquí no nos interesan los tiempos de las empresas o del Municipio, incluso si son o no 11 cuadras; lo que nos interesa remarcar es el recorte que, ante un 
total de cuadras (reales o no) a asfaltar, que dejarían un sector en la misma situación actual, alguien del barrio las señala como "todo el barrio".

Del mismo modo en que la ciudad denota una plasticidad contra la que SCAC lucha, el propio barrio parecería denotar cierta plasticidad en su interior, donde los vecinos que ejercen cierto poder dentro de la organización barrial escinden simbólica y materialmente esas 11 cuadras asfaltadas y afirman, que las mismas son "todo el barrio". Podríamos ver esto como la periferia construyendo su propia periferia, y quizás también lo sea, más aún que dominantes/dominados, pero al afirmar esto sin profundizarlo se corre el riesgo de analizar las relaciones de poder sobre la base de un rígido eje hegemónico/subalterno que vería a Mariano Moreno en un extremo y a SCAC en el otro. Incluso desde una mirada amplia sobre el hacer la cuidad, donde dicha antinomia parecería ser más pertinente, se estaría soslayando el nivel de la construcción simbólica y de la producción de sentidos, que si bien se dan a un nivel barrial que podría caracterizarse como "micro", tiene efectos sobre el hacer la ciudad, en tanto el asfalto coloca a SCAC un poco más "cerca" de Mariano Moreno, un poco más cerca del "hacer elástico", pero no a todo SCAC, sino a esas 11 cuadras que, para quienes detentan cierta posición en la organización barrial, "son todo el barrio"; el resto ocuparía una doble dimensión, en relación al barrio y a la ciudad toda, en el "hacer plástico".

La lucha en que se involucra SCAC por el asfalto no tendría como objetivo enfrentarse a (o poner en evidencia) la desigualdad estructural en torno al acceso a los consumos colectivos, o dicho de otra forma: luchan por no ser lo que se dice que son, en la medida en que la lucha no niega la existencia de un otro "peligroso", de hecho durante las protestas se señalaron otras zonas como "bravas". El barrio "peligroso" existe, pero no es éste. Lo "peligroso" se halla en constante movimiento, la mácula se desplaza sobre los barrios, hoy es SCAC, ayer fue Pueblo Nuevo, mañana será otro, como señala Ana Silva, "Lo intolerable no cesa de desplazarse y recomponerse, se trata de una norma y un límite históricamente constituidos y por lo tanto susceptibles de relatividad temporal; hoy no sabemos cuáles serán los intolerables de mañana" (Silva, 2016: 136). 


\section{De la ciudad negada a la ciudad luchada}

Si la forma de la ciudad se considera "cristalizada", lo que aquí vemos desde la metáfora de la plasticidad, entonces existiría una ciudad "terminada", y no sería posible luchar por "hacer la ciudad" en una ciudad "terminada". Distinguiendo, analíticamente por supuesto, el presente de la dimensión histórica: si nos posicionamos desde la segunda, la ciudad estaría siempre haciéndose (podemos ver ese hacer a través de la historia), es en el presente donde parecería "estar terminada", (por ejemplo cuando un barrio reclama por obras). La ciudad que está siempre haciéndose en la dimensión histórica es lo que construiría poder, en su sentido más amplio, en los territorios como resultado de esa lucha constante que se da en el presente.

El panorama de la lucha por la ciudad, o por el derecho de hacer la ciudad, nos plantea, en definitiva, la pregunta por el rol estructural de la misma, que desde la reivindicación de las luchas sería el acceso garantizado a los consumos urbanos producidos por el conjunto de la sociedad. Analizar el rol de la ciudad desde la dimensión de la negatividad, es decir, y siguiendo a Gravano (2013), por lo que la ciudad no otorga a quienes la producen, recuperando por un lado el carácter (si bien tentados a decir la "naturaleza") capitalista de la ciudad, y por el otro, la desigualdad estructural de la misma. Cabe la pregunta de si entonces el rol estructural de la ciudad sería, no solo el de garantizar el acceso a los consumos, sino también el de no hacerlo.

Si la lucha por el derecho a la ciudad, en tanto catalizador de las acciones colectivamente emprendidas, motoriza la producción y reproducción de la vida urbana, entonces la propia ciudad necesitaría garantizar tanto la desigualdad como el derecho para asegurar su reproducción. Esto pondría en tensión el rol estructural imaginado/construido desde la visión de la lucha colectiva (igualdad en el acceso) y el rol estructural imaginado/construido desde el sistema capitalista (desigualdad para la reproducción). Pretendemos pensar a ambos como parte de una relación dialéctica que contiene tanto lo que espera el capital como lo que esperan las luchas que se dan en la ciudad. En definitiva, de la ciudad negada emerge la ciudad luchada. 


\section{Referencias}

BOGGI, Silvia\& GALVAN, Nora. Ni chicha ni limonada. Ponencia presentada en el IX Congreso Argentino de Antropología Social. Posadas, Misiones. 2008.

BROOK, Gabriela. Fomentismo y participación política en el Partido de Olavarría. Tesis de Licenciatura en Antropología Social (inédito). FACSO-UNICEN. 1997.

BOURDIEU, Pierre. What Makes a Social Class. Berkeley Journal of Sociology, $\mathrm{N}^{\circ} 32$, p.1-18. 1987.

BORJA, Jordi. La Ciudad Conquistada. Madrid, España: Alianza Editorial. 2003.

CASTELLS, Manuel. Movimientos Sociales Urbanos. Buenos Aires: Siglo XXI. 1974

FERNÁNDEZ, Gimena \& DIOMEDI OLLIER, Santiago. " JJa! Que raro en el 'ESCA"

Análisis de los imaginarios en torno a un barrio de Olavarría. Ponencia presentada en las V Jornadas de Antropología Social del Centro. FACSO UNICEN. 2015.

GIDDENS, Anthony. La constitución de la sociedad. Buenos Aires: Amorrortu. 1995.

GIMENEZ, Gilberto. Introducción a la sociología de Pierre Bourdieu. Colección Pedagógica Universitaria No. 37-38 enero-junio/julio-diciembre 2002, p.1-11. 2002.

GRAVANO, Ariel (comp.). Imaginarios sociales de la ciudad media. Emblemas, fragmentaciones y otredades urbanas. Estudios de Antropología Urbana. Tandil: Centro Editor de la UNICEN. 2005.

GRAVANO, Ariel. Antropología de lo urbano. Universidad Nacional del Centro de la Provincia de Buenos Aires, Tandil. 2013.

GRAVANO, Ariel. Antropología de ciudades medias: tres hipótesis sobre la relación entre sistema urbano e imaginarios. Ponencia presentada en el XI Congreso Argentino de Antropología Social. Rosario, Santa Fe. 2014.

GRAMSCI, Antonio. Análisis de las situaciones. Relaciones de fuerzas. Nueva Antropología [en linea] IV (diciembre): [Fecha de consulta: 26 de julio de 2016] Disponible en:<http://www.redalyc.org/articulo.oa?id=15901602> ISSN 0185-0636. 1980

HARVEY, David. Diecisiete contradicciones y fin del capitalismo. Quito: IAEN. 2004 MEZZANO, A. en TABORDA, A. \& LEOZ, G. (comp.). Psicología Educacional en el Contexto de la Clínica Socioeducativa. Volumen II. Nueva Editorial Universitaria. Universidad Nacional de San Luis. 2013.

ROMERO, Yuri. Tramas y urdimbres sociales en la ciudad. Revista Universitas humanística, № 61, enero-junio de 2006, pp. 217-228. Bogotá - Colombia. 2006.

SILVA, Ana. Sentidos y valores del "trabajo", o las fronteras morales de la ciudanía. En: GRAVANO, Ariel (comp.). Ciudades vividas. Sistemas e imaginarios de ciudades medias bonaerenses. Buenos Aires: Café de las ciudades; pp. 135-152. 2016.

SOSA, Rosana. La marca en el orillo. Prioridades educativas, imaginarios urbanos y perfil productivo de la ciudad de Olavarría. Tesis Doctorado en Ciencias Sociales UBA. (Inédito). 2014.

SOSA, Rosana. Sobre héroes y gestas: lo estructural y lo imaginario en las narrativas urbanas acerca de la hechura de la ciudad. Ponencia presentada en las V Jornadas de Antropología Social del Centro. FACSO UNICEN. 2015.

SABAROTS, Horacio y SARLINGO, Marcelo. "Los caminos de la organización popular barrial: límites y potencialidades de una experiencia". En: Gravano A. (Comp.). Miradas urbanas - Visiones barriales. Editorial Nordan. Montevideo; pp. 203-242. 1995.

Recebido em: 20/10/2017.

Aprovado em: 15/11/2017. 